\title{
Vedat Örfi Bengü'nün Çıldıran Adam Romanında Sosyete ERHAN GÜRPINAR*
}

\begin{abstract}
Öz
Geç modernleşen bir ulus devletin kanonik edebiyatında incelenmeye değer bulunmayan popüler romanlar genelleştirilmiş bir ön yargıyla küçümsenir, değersiz bulunur. Aslında bu genelleştirilmiş ön yargı toplum sorunlarını derinlemesine incelemede engeldir. Kültürel yapımızı doğru tespitlerle araştırmak istiyorsak, geniş halk kitlelerine ulaşan ve hatta anlattıklarıyla bu kesimi yönlendiren bu romanları her ne kadar kurgusal ve estetik zaafları olsa da incelemeliyiz. Bütüncül bir edebiyat sosyolojisi için bu şarttır. Vedat Örfi Bengü'nün Çıldıran Adam romanı, Türk toplumunun hâlâ sıkıntısı olan sosyete olgusunu nedenleri ve sonuçları bakımından değerlendiren popüler bir romandır. Aşırı modernleşmenin sonucu olan sosyetik zihniyet, özünü kaybeden bir toplumun yaşadığ buhranlar günümüz popüler romanlarının da konularıdır. Popüler romanlarda anlatılan aşırı sosyete yaşamı, edebiyat sosyolojisi alanında incelemeye değer bir konudur.
\end{abstract}

Anahtar sözcükler: Popüler roman, sosyete, toplumsal denge, aile, metin analizi

Abstract

HIGH SOCIETY IN VEDAT ÖRFI BENGÜ'S NOVEL “ÇILDIRAN ADAM”

Popular novels that were ignored in a canonical literature of a late-modernizing nationstate are underestimated and found worthless by a generalized prejudice. In fact, this generalized prejudice is an obstacle to examine the social problems profoundly. If we want to investigate our cultural structure correctly, we must analyze these novels that reach the large masses and even influence them with their narrations even though they have some fictional and aesthetic weaknesses. This is essential for an organized sociology of literature. Vedat Örfi Bengü's novel "Çıldıran Adam" is a popular novel that evaluates the phenomenon of high society that is still a problem of Turkish society in terms of causes and consequences. The high society mentality resulting from the extreme modernization, the crisis in which a society loses its essence are also topics of contemporary popular novels. The extreme life of high society described in popular novels is a worthwhile subject in the field of sociology of literature.

Keywords: Popular novel, high society, social balance, family, text analysis

\footnotetext{
* Muğla S. K. Üniversitesi Sosyal Bilimler Enstitüsü TDE doktora programı, erhan7gurpinar@gmail.com
} 


\section{GíRIŞ}

opüler romanlar hep kanon dışına itilmiş, sadece eğlendirme maksatlı
çalakalem yazılan, derinliği olmayan romanlar olarak görülmüştür. Aslında bu
romanlar toplum yapısını incelemede sosyolojik derinliği olan romanlardır. Her ne kadar amaçları kitap satışlarından para kazanmak olsa da bu romanlar toplumda yaşanan olumsuzluklara duyarsız kalmamışlardır.

Vedat Örfi Bengü'nün Mısır'da Kan adıyla oynanan tiyatro eserini roman türüne uyarlayarak yazdığı Çıldıran Adam popüler romanı, aşk ve ızdırap romanı olduğu kadar geç modernleşen bir ulus devletin oluşturmaya çalıştığı ideal günlük yaşamın eksen kaymasının romanıdır. Vedat Örfi Bengü ifrat (taşkınlık) derecesinde modernleşmenin sonucu oluşan sosyete kavramının ülkemizde yozlaşarak modernleşme, özgürlük, serbestlik adı altında her şeyi yapabilme gibi taşkınlığa evrilmesini eleştiren bir roman yazar.

\section{İNCELEME}

Roman isimlerini daha sonra öğrendiğimiz Raika ve Nihat arasında yaşanan aşkla başlar. Bu yaşanan aşk hikâyesinde gençler gençliklerinin verdiği heyecan ve tecrübesizlikle hata yaparlar. Bu hata sonucunda Raika'nın namusu kirlenir. Kandırıldığını anlayan Raika, Nihat'tan intikam alma hissiyle dolar. Bu hisle hayat kadını olan Raika Nihat'ın abisi olan Doktor Selim ile bir gece işret âleminde tanışır. Doktor Selim, Raika'nın hâline acır. Onunla evlenmeye ve onu bu kötü durumdan kurtarmaya karar verir. Evlenirler fakat kısa bir mutluluk devresinden sonra evlilikte sorunlar baş gösterir. Bu sorunlar, Doktor Selim'in bir bilim adamı olarak aşırı çalışma düzeni ve Raika'nın gençliğini yaşama isteğidir. Raika'nın yaşama isteği ile Doktor Selim'in çalışma azmi çatışır. Bu çatışmada Selim, tutkuyla bağlı olduğu bilimsel çalışmalarını bırakarak Raika'nın istediği adam olma kararını verir. Fakat bu kolay olmaz. Çünkü Raika'nın istediği sosyete adamı olma düşüncesi, Selim için iğrençtir. Her ne kadar iğrenç olsa da Selim namusu ve şerefi için buna katlanır. Tek isteği eşi Raika'nın kendisini aldatmaması veya kendisini terk etmemesidir.Tam bu esnada Selim'in kardeşi Nihat gelir. Raika için bu olay intikam alma fırsatıdır. Fakat bu son derece korkunç olaylara neden olur. Nihat, abisinin Raika ile yaşadığı macerayı öğrenmesini istemez. Bu yüzden Raika'nın her dediğini yapar. Raika en son Nihat'ın kendi yatak odasına gelmesini ister. Nihat Raika'da bulunan aşk mektuplarını almak amacıyla teklifi kabul eder. Bu arada Nihat'ın eski sevgilisi olan Bedia bunu öğrenir ve öğrendiklerini Selim’ e söyler. Selim ihanete uğrayacağını düşünerek Nihat'ın Raika'nın yatak odasına girişini bekler. Fakat zavallı Selim, bu giren kişinin kardeşi olduğunu bilmemektedir. Kıskançlık bunalımında çıldıran Selim, odadan çıkan kardeşini elindeki neşterle öldürür. Daha sonra ellerindeki kanla Selim, eşini öldüreceği sırada öldürdüğü kişinin kardeşi olduğunu öğrenir. Raika'nın 
söylediklerinden sonra daha da çıldıran Selim en sonunda eşi Raika'yı boğarak öldürür. Böylelikle daha önceden aynı olayı yaşayan üniversiteden hocası Doktor Necmettin'in kaderini Doktor Selim de yaşar. Selim yaşadığı bu acıya dayanamaz ve hastanede ölür. Olaylar Selim ile Nihat'ın dadısının mezar başlarında bu iki genç insan için ağlayışı ile sona erer.

Roman zaman olarak 1940-1950 yılları arasında geçmektedir. Atatürk'ün ölümüyle başlayan değişim siyasi yaşamda olduğu kadar gündelik yaşamda da görülür. Ülke, Cumhuriyet reformlarının ideal düzeni yaratmak için oluşturduğu kuralcı tutumun sancıları ve çok partili yaşama geçiş çalışmaları gibi siyasi çatışmalar eksenindedir. Bu siyasi çatışmaların yanında ülkede yavaş yavaş tüketim olgusunu oluşturacak kapitalist etkiler görülmeye başlar. Modernleşmenin etkisiyle insanlar boş zamanlarında radyo dinler, gazete okur, tiyatroya veya sinemaya gider. Ülkede kapitalist yapı bu gündelik yaşamdaki boş zaman değerlendirmeleri üzerine şekillenir. Aşırı tüketme bilincini yerleştirebilmek için gazete ve sinema gibi yayın ve yayım organlarını kullanır. Bol resimli gazetelerin çıkması, bu gazetelerde görsel anlamda şık, çağdaş kadınların ve erkeklerin yer alması moda tüketiminin önünü açar. Basın hayatında görülen bu değişim sinema ile desteklenir. Hollywood sinemasının etkisi bu dönemlerde daha fazla hissedilmeye başlar. Amerikan sinema endüstrisinin etkisine giren toplumdaki değişim idealist entelektüel çevrelerde tartışılan konular olur. Siyaset dışı olan bu konuların entelektüel çevrelerde tartışılması eski-yeni tartışmaları kadar, cumhuriyet idealleri çerçevesinde eleştiri konusudur. Her türlü etki karşısında esnek bir yapı oluşturan kapitalist düzen, toplumsal yapıyı istediği şekle dönüştürmeye çalışır. Bu değişim en çok yeni yetişen genç nesil üzerinde görülür. Genç k1z ve erkeklerin Amerikan özentisi, ülkenin Amerikanlaşma sürecini başlatır. Bu değişimde en çok eleştirilen konulardan biri de sosyete kavramıdır.

Topluluk, toplum, cemaat anlamına gelen bu kelime daha çok bugün jetsosyete anlamında, gelir düzeyi yüksek ve kendilerine özgü yaşama biçimi olan topluluk anlaminda kullanılır (www.tdk.gov.tr. e.t: 12/09/2017). Bu olguda en çok eleştirilen kızlarımız ve kadınlarımızdır. Genç kızlarımızın davranışları, alışkanlıkları, idealleri, rüyaları yeni oluşan görsel basının ve sinemanın etkisiyle değişir. Bu farklılaşma eski yeni tartışmaları kadar Cumhuriyet reformlarını savunanların da eleştiri konusudur. Lüks yaşam artık genç kızların ideali olur. Eskinin genç kızları gibi çeyiz sandığına el işleri yapmak yerine kütüphane raflarına aşk romanları dizer, model kataloglarını karıştırır, sinemada dudak dudağa aşk yaşayan çiftleri izler. Hastalıklı melankolik yapıdaki genç kızlar için moda, lüks yaşam ve 
sosyete gençlik rüyalarıdır. Kadınlar ise evinde kocasını bekleyen, kocasına itaatkâr tutumlarını bir kenara bırakarak balolara, operalara, sinemalara giden ve bunu ihtiyaç olarak gören bir kişiliğe dönüşmüşlerdir. Hatta daha da ileri gidilerek kadınlar, poker ve içki masalarında kadınlara özgü erdemlerini bir kenara atarak, serbest ve özgür olma düşüncesiyle sadakatlerini de unutarak yaşamaya başlarlar. Genç erkekler de Bobstil yaşam tarziyla bu yoz düzene ayak uydururlar.

Çıldıran Adam romanı, aşırı modernleşmenin sonucu olan ifrat (taşkın) derecedeki sosyetik yaşamın, toplumsal yapıyı nasıl yok ettiğini anlatır. İfrat (taşkınlık) toplumsal yapıyı öldürecek içtimai bir kanserdir. Bu hastalık iyileştirilmezse tüm toplumsal yaşam ölecektir. Romanın yazıldığı dönemde bilhassa sosyete olgusu üzerinde bu tartışmalar görülür.

“Cumhuriyet döneminde Otuzlu yıllardan itibaren modernleşme eğilimlerinin yoğunlaştığı ve bunun tüketim alışkanlıklarıyla örtüştügü gözlenir. Gündelik yaşama ilişkin etkileri, dergi ve gazetelerde rejimin hedefleriyle eşgüdümlü olarak tartışıldığı kadar, iç sayfalardaki tefrika ve fotoğraflarda, özellikle karikatürlerde yer almaktadır. Bir sosyal görev olarak, kontrolden çıtığı / ifrata kaçtı̆̆1 düşünülerek Batılılaşma ve tüketim taleplerine karşı çıkıldı̆̆g, diretildiği de görülmektedir. Gündelik yaşamın sürekli tanzim edilmesi çabası, kontrolden çıkacağı endişesinin hâkim olduğuna işarettir." (Cantek 2005: 80)

Doktor Selim 'büyük bir insanlık davasına hizmet eden' idealist bir bilim adamıdır. İnsanlık yararına yapabileceği en önemli çalışmanın ne olacağı sorusunu çok düşünür ve bunu o zamanın melun hastalığı olan kansere çare bulmada karar verir. Lakin yaşayacağ olaylar kanser hastalığının nerede oluştuğunu kendisine acı bir şekilde gösterir. Kanser vücutlarda değil ruhlardadır.

Dünyaca başarılı bilimsel buluşlar yapacağı düşünülen Selim, kendisi gibi bilim adamı olan fakat bilimin çalışma ruhunu kaybetmiş, dünya zevkleri ile bilimsel çalışmaları dengede tutmaya çalışan diğer bilim adamları tarafından yolundan alıkonulmaya çalışılır. Arkadaşları olan Doktor Faruk ve Doktor Macit idealist olan Doktor Selim'i ilk önce bir şeyler içmek için davet ederler. Daha sonra iş, gece âlemlerinde eğlenmeye doğru gelişir. Bu gece âlemine katılmak istemeyen Selim mütevazı mizacından dolayı reddedemez. Onlara katılır. Evli de olan bu arkadaşlar bu âlemde genç kızlarla düşüp kalkarlar. Doktor Macit, Doktor Selim'e nasihat verirken söyledikleri aslında o zaman için okumuş ve bilimle uğraşması gereken bilim adamlarının yaşantılarının bir özetidir:

"Hayatta yalnızlığa bu derece katlanabildiğine şaşıyorum, Selim. Ne zevk düşünüyorsun, ne eğlence!.. Kadınsız hayat olur mu, a mübarek?.." (Bengü 1944:

11) 
“Biz de yerlerimizde sayıyor değiliz a, canım. Çalışabilmek için yalnızlık ve mahrumiyet mi şart?.. Dünyaya bir defa geliyoruz. Her türlü zevkten, eğlenceden nasibimizi almak hakkımız. Sonra... bunlar birer ihtiyaç, unutma!.. Vücut dinlenmek, ruh beslenmek, dimağ tazelenmek ister. Yorgun dimağını mesela bir konserde olsun gidip musikinin tesirlerile tazelemeyi aklından geçirmiyorsun. Kuracağın bir yuva saadetinin hayatına yepyeni bir kuvvet verebileceğini düşünmek dahi istemiyorsun. Bak, şaka bir yana, kırkını geçtin, daha evlenmeğe niyet bile etmedin?.." (Bengü 1944: 11)

Doktor Faruk da aynı görüştedir:

“Sen, ilim âleminin pek haklı övündüğü müstesna şahsiyetlerinden birisin, Selim. Senden çok büyük hizmetler bekleniyor, çalışmalısın, evet!.. Ama, ne de olsa bir insansın, unutma!.. İnsan vücudu, bitmez tükenmez bir enerji kaynağı değildir. Her bakımdan beslenmek ister, Macidin dediği gibi!.. Mahrumiyetler içinde yalnız didişen vücut, uzun müddet beklenilen randımanına zaten yaratamaz." (Bengü 1944: 11)

Bu bilim adamları hayatın kendisine sunduğu nimetlerden yararlanan güya çalışan fakat hovardalıkta ve işret âlemlerinde isim yapmış, mesaileri bittiğinde işret âlemlerine koşan bilim adamlarıdır. Burada toplumsal yapıda denge unsuru belirtilir. Doktor Selim'in aşırı çalışma düzeni eleştirilir. Fakat verilen rol modeller olan Doktor Macit ve Doktor Faruk Beyler sosyete yaşamının nimetlerinden yararlanan, bilimsel çalışmayla özel yaşamlarını sözde dengede götüren olumsuz tiplerdir. Selim'in bu arkadaşları modernleşme çılgınlığının erkek olumsuz tipleridir.

“Doktor Faruk tam mânasile bir cemiyet adamıydı. Neşelere neşeler katıyor, zarif nükteleriyle konuşmalara cazip zenginlikler veriyordu. Genç kızlar da bu sofradan pek hoşlanmışlardı." (Bengü 1944: 13)

Arkadaşlarının yoğun ısrarlarına dayanamayan, mütevazı Selim işret alemine istemeyerek girer. Böyle bir ortama yirmi senedir girmeyen Selim, arkadaşlarını kıramaz ve bu âleme dair her şeyi istemeye istemeye onaylar. Bu âlem maskelerin takıldığı insanların bile bile aldandığı/aldattığı ortamlardır:

"Bu içki âleminin görünüşü ne kadar da samimiydi!.. Konuşmalarda, duygularda en küçük bir ahenksizlik bile yoktu ve buradaki insanlar, uzun yıllardan beri en candan duygularla kaynaşmışlardı. Öteki yana dönse, beriki bir isteği olup olmadığını soruyor, sağdaki yüzünü buruştursa soldaki hemen ilgileniyordu. Ya gerçekte?.. Bu âlemde yaşamayan veya yaşayamayacak olan tek şey elbet samimiyetti. Kimi kimi aldatıyordu?.. Tabii kimse kimseyi!.. Hepsi de bile bile lades demişlerdi. Bir kısmı kana kana aldatacak, öbür kısmı isteye isteye aldanacaktı." (Bengü 1944: 16) 
$\mathrm{Bu}$ yozlaşmış ortamda erkekler zevk ve şehvet için aldanacaklar, kadınlar ise bu zevk düşkünü erkeklerden istifade için aldatacaklardır. Bu kadınların amaçları bir eş gibi erkekleri korumak ya da kollamak değil intikam hissiyle erkekleri boğmaktır. Bu ortamda Selim, Raika ile tanışır. Selim kendisine teklif edilen eş seçme hakkını Raika'dan yana kullanır. Raika ile Selim arasında geçen konuşmalar Selim'i etkiler. Raika, Selim'in Büyükada'daki köşkünün komşusunun terbiyeli ve güzel kızıdır. Gençliğinin ve tecrübesizliğinin neticesinde kötü yola düşmüştür. $\mathrm{Bu}$ yoz ortamın kurban kızlarından biridir. O artık erkeklere düşman bir kadındır. Selim bu konuşmalardan sonra Raika'nın ruhunun kirlenmediği kanaatine varır. Raika'nın kendisini bu hayattan kurtaracak erkeğe Tanrı gibi tapacağını söylemesi Selim'i etkiler. Ona acır, onunla evlenmeye karar verir. Onun kötü hayatı mesut günlerle örtülecek ve unutulacaktır. Dediği gibi de olur. Evlilikten sonra yaşanan mesut günler kötü hayatını ve geçmişini unutturur.

Yardımsever, altın gibi kalbi olan mütevazı bir kişiliğe sahip olan Selim, muhtaçlara yardım eden, bu uğurda para harcamaktan çekinmeyen ideal bir tiptir. Sürekli kendisine nasihat veren birileri vardır. Bu nasihatler genelde bir kadını sevmek, sevdiği bu kadınla aile ve çocuk saadetini tatmaktır. Hayatın nimetlerinden olan bu hisler onun bilim adamlığı ve kocalığı arasında sıkışıp kalmasına neden olur. Önceleri mutlu mesut bir evlilik sürdürürken yavaş yavaş değişimin getirdiği sancılar başlar. Selim'in bilimsel çalışmaları karısı Raika'yı rahatsız eder. Raika genç ve güzel bir kadındır. Sosyete ortamlarına girmek buralarda gençliği yaşamak ister. Yazara göre çarpışma Selim'in itiyadı ile Raika'nın “cibilliyeti” arasındadır. Selim'in aşırı çalışma düzeni Raika'yı sıkar, bunaltır ve en sonunda isyan ettirir. Selim'in “itiyadı" ile Raika'nın “cibilliyeti” çatışır. Raika'nın ev hanımlığı sokak kadınlığına yenilir. Bu yenilgi onun "cibilliyetindendir". Bu çatışma modernleşme ekseninde olan Türk toplumu için dönüşümün sancılarıdır. Kadının isyanı, çekirdek aile düzeninin de bozulduğunun göstergesidir.

Kendisini kötü hayattan kurtaracak erkeğe Tanrı gibi tapacak bir kadın olan Raika bu sözünü de değişime uğratır.“-Beni kurtarana, evet!.. Beni, yalnızlığın ve bunaltının mezarına gömmek isteyene değil!.." (Bengü 1944: 38) diyerek güçsüz durumdan güçlü duruma geçer. Selim'i ayrılmakla tehdit eder. Bu durum Selim'i korkutmağa başlar. Raika'nın yaşamak istediği hayat sosyetik yaşamdır. Fakat bu hayat taşkın modernleşmenin neticesidir.

Raika'nın Selim'e hitaben "Siz esas kanseri evinizde açıyorsunuz" diyerek ihanet kanseriyle tehdit etmesi Selim'i çıldırtır. Bilimsel çalışmalarından kendi namus ve şerefi uğruna vazgeçer. Selim'deki bu zoraki dönüşüm aslında bir bilim adamının toplumsal yapı 
kıskacında yaşadığı zorluklardır. Namusu ve şerefi için bilim adamlığını bırakıp istemeye istemeye sosyete adamı olmaya çalışır. Lakin bu zorlama onu içten içe yıpratmaktadır: "Ya meslek feda edilecekti(r), ya şeref!..." (Bengü 1944: 58) Değişimden sonra evde sosyete yaşantısıyla adeta bir tımarhane kurulur. Raika'nın sosyete anlayışı "çılgın bir serbestlik, yuva saadetlerini tırmalayan bir taşkınlık, karşılıklı saygı kaidelerini ezen bir aşırılıktı(r)" (Bengü 1944: 59)

Doktor Selim'e göre sosyete kelimesi yanlış anlamlandırılır. Ona göre ülke kalkınmasında büyük bir yeri olan sosyete, ülkeyi ahlaki yozlukta yok olmasına neden olacak toplumsal bir kargaşaya götürmektedir. Taklit budalası bir topluluğa dönüşen bu sosyete yaşantısı delilerin yaşadığı bir tımarhanedir. Kanser hastalığına çare olmak isterken toplumumuzu kanser gibi öldüren aşırı sosyetik yozlaşmaya çare bulamaz. O artık “yeryüzündeki kanseri bulmağa çalışırken içtimai kanseri yuvasında gören zavallı ilim adami(dir)"

O günkü tıbbi anlayışla kanser olan uzuv kesilir. Böylelikle sağlam olan diğer uzuvlar kurtarılır. Toplumsal yapıda da kanser olan uzuv kesilmeli, sağlam olan diğer yapı unsurları kurtarılmalıdır. Bu anlamda kanserli olan uzuv sosyete yaşantısıdır. Hastalıklı olan sosyetik yapı, bu müzmin hastalığı diğer yapı unsurlarına bulaştırmamalıdır. Toplumsal yapıyı yaşatmak istiyorsak kanser olan sosyetik yaşantı sonlandırılmalıdır.

Yazar romanın sonunda bu toplumsal yozlaşmanın nedenini açıklar. Ona göre bunun nedeni düşünüşte, harekette, istekte, cesarette ve korkuda taşkınlıktır. Her şeyin bir sınırı vardır. Bu sınırlar aşılmamalı, dengede olmalıdır. Denge olmadığı zaman "taşkınlık bir Azrail fırçası gibi matemin korkunç tablosunu yaratır, mübalağa bir matem şairi gibi yeryüzünün en sızlatıcı mısraını okur"' (Bengü 1944: 95)

\section{SONUÇ}

Eğlencelik ve para kazanma amaçlı yazıldığı düşünülen popüler romanlar sosyolojik derinliği olmayan, incelenmesi gereksiz eserler olarak görülür. Tümü için bir genelleme yapılarak verilen bu yargı yanlıştır. Bu romanlar arasında toplumsal sorunları teşhis eden, nedenlerini açıklayan sosyolojik derinliği olan romanlar da vardır. Bu genellemeci yargıdan vazgeçilerek bu popüler romanlar incelenmelidir.

Ulusal kanon geçmişte üretilen eserlerin hangilerinin önemli olduğunu ve hangilerinin geleceğe taşınacaklarını (Uğur 2009: 78) belirlediği için bütüncül bir edebiyat sosyolojisi çalışmalarında ulusal kanon tarafından baskılanan bu eserler farklı bir bakış açısıyla yeniden değerlendirilmelidir.

Kapitalin gücü gündelik hayatın seyrindedir. Günlük hayat iktidarın gücünü belirler. Halkın o dönemin (1940-1950) kısır siyasal ve toplumsal konularından sıkılması, kendisine 
konformist bir yaşam yaratma isteği, o dönem insanını Amerikan yaşam tarzını arzulamaya, düşlemeye götürmüştür. Basım ve yayın araçları halkın önüne bu yönde modeller oluşturmuştur. Hollywood sinema endüstrisi ütopik, ulaşılmaz, şaşalı yaşamları melankolik aşkla süsleyerek Türk halkının düşlerine yerleştirmesi, sosyete yaşantısını özendirmesi kapitalist dönüşümün sancılarıdır. Bu sancılı dönüşüm 1930'lu yıllardan sonra siyasal ve toplumsal hayatta etkili olmuştur.

Vedat Örfi Bengü toplumda kansere dönüşen sosyete olgusunu romanında konu edinir. Günümüzde hâlâ tartışılan bir konu olan sosyete, romanda anlatıldığı şekilde taşkın bir hâlde devam etmektedir. Taklitçi Amerikan etkisi toplumsal yapıda duyumsanmaktadır. Çok eşlilik, gece yaşamları, çok sık boşanmalar ve hatta ensest ilişkiler toplumsal çöküntüyü hızlandırmaktadır. Yazarın romanında belirttiği gibi düşünüşte, harekette taşkınlık devam ettiği müddetçe bu yozlaşma devam edecektir.

\section{KAYNAKÇA}

Bengü, Vedat Örfi (1944). Çıldıran Adam. İstanbul: Arif Bolat Kitabevi

Cantek, Levent (2005). Gündelik Yaşam ve Basın (1945-1950): Basında Gündelik Yaşama Yansıyan Tartışmalar. Yayımlanmamış Doktora Tezi. Ankara: Ankara Üniversitesi.

Koçakoğlu, Bedia (2017). “Cumhuriyet Dönemi Türk Romanı”. Ed. Oktay Yivli. Modern Türk Edebiyatı. İzmir: Günce Yayınları.

Uğur, Veli (2009). 1980 Sonrası Popüler Roman. Yayımlanmış Doktora Tezi. İstanbul: İstanbul Üniversitesi.

Yalçın, Alemdar (2017). Siyasal ve Sosyal Değişmeler Açısından Cumhuriyet Dönemi Türk Romanı I (1946-2017). Ankara: Akçă̆ Yayınları. 